\title{
The Progressive Development of Turbulence Statistics and Its Impact on Wind Power Predictability
}

\author{
Thomas Woolmington \\ Technological University Dublin, thomas.woolmington@tudublin.ie \\ Keith Sunderland \\ Technological University Dublin, keith.sunderland@tudublin.ie \\ Jonathan Blackledge \\ Technological University Dublin, jonathan.blackledge@tudublin.ie
}

See next page for additional authors

Follow this and additional works at: https://arrow.tudublin.ie/engscheleart2

Part of the Electrical and Electronics Commons

\section{Recommended Citation}

T. Woolmington, K. Sunderland, J. Blackledge \& M. Conlon., "The progressive development of turbulence statistics and its impact on wind power predictability, Energy, vol. 77, pp. 25-34, 1/12/2014 2014.

http://dx.doi.org/10.1016/j.energy.2014.03.015

This Article is brought to you for free and open access by the School of Electrical and Electronic Engineering at ARROW@TU Dublin. It has been accepted for inclusion in Articles by an authorized administrator of ARROW@TU Dublin. For more information, please contact arrow.admin@tudublin.ie, aisling.coyne@tudublin.ie, gerard.connolly@tudublin.ie.

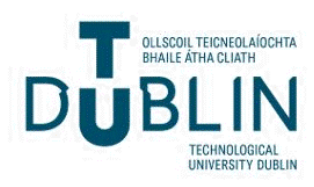




\section{Authors}

Thomas Woolmington, Keith Sunderland, Jonathan Blackledge, and Michael Conlon

This article is available at ARROW@TU Dublin: https://arrow.tudublin.ie/engscheleart2/101 


\title{
THE PROGRESSIVE DEVELOPMENT OF TURBULENCE STATISTICS AND ITS IMPACT ON WIND POWER PREDICTABILITY
}

\author{
T. Woolmington ${ }^{1^{*}}$, K. Sunderland ${ }^{2}$, J. Blackledge ${ }^{3}$ and M. Conlon ${ }^{4}$
}

1. School of Electrical and Electronic Engineering, Dublin Institute of Technology, Ireland; email: thomas.woolmington@dit.ie

*corresponding author

2. School of Electrical and Electronic Engineering, Dublin Institute of Technology, Ireland; email: keith.sunderland@ dit.ie

3. School of Electrical and Electronic Engineering, Dublin Institute of Technology, Ireland; email: jonathan.blackledge@ dit.ie

4. School of Electrical and Electronic Engineering, Dublin Institute of Technology, Ireland; email: michael.conlon@ dit.ie

\begin{abstract}
Wind resource assessment is a critical parameter in a diverse range of considerations within the built environment. Engineers and scientists, engaging in building design, energy conservation/application and air-quality/air-pollution control measures, need to be cognisant of how the associated wind resource imposes increased complexities in their design and modelling processes. In this regard, the morphological heterogeneities within these environments, present significant challenges to quantifying the resource and its turbulent characteristics.

This paper presents three aspects of turbulence assessment within the built environment. Firstly, an analysis of how turbulence is currently quantified is considered. The industry standard, Turbulent Intensity (TI) is compared with a proposed alternative metric described as Turbulent Fourier Dimension modelling $\left(\mathrm{T}_{\mathrm{Df}}\right)$. Secondly, the application of the turbulence assessment is considered with respect to how TI affects the productivity of small/micro wind turbines in complex environments though Gaussian distribution analysis. Finally, an extended discussion on current developments such as the concept of a turbulence rose and the ongoing development of statistical modelling is presented.
\end{abstract}

\section{KEYWORDS:}

Turbulence, Wind Power, Urban Environment, Wind Turbine

\section{HIGHLIGHTS}

- Introduces the Turbulent Fourier Dimension $\left(\mathrm{T}_{\mathrm{DF}}\right)$ as a complimentary statistic

- Comparison of $\mathrm{T}_{\mathrm{DF}}$ with the Turbulence Intensity (TI) metric

- Quantifies The Effects TI has on power prediction using Gaussian analysis

- Discusses the issues of PDF based power prediction modelling

- Proposes a synthetic time series model as an alternative power prediction model 


\section{INTRODUCTION}

The ability to harness kinetic energy from laminar wind flow is governed by an adjusted kinetic energy formula.

$$
P=\frac{C_{p} \cdot \rho \cdot A \cdot u^{3}}{2}
$$

where the mechanical output power $(P)$ is a function of the performance coefficient of the turbine $C_{p}$, the density of air $(\rho)$, the area swept by the turbine projected in the direction of the wind $(A)$ and wind-speed $(u)$.

In terms of wind energy conversion, the Betz limit, stipulates that the maximum possible conversion coefficient of a wind rotor is 59.3\%. However, as a consequence of (aerofoil) blade roughness, wake effects, hub loss and tip losses system efficiency is significantly reduced resulting in efficiencies in the range of 30-35\% [1]. It is also noted however that Betz Limit is wholly based on a laminar flow model and as such should not be used as a guide in turbulent environments. This poses significant problems for the industry, as the ability to quantify the wind resource in an urban environment accurately is currently questionable. Theories and mathematical models have been developed primarily from atmospheric climatology perspective and then subsequently adapted and amended to suit the wind industry [2].

Computational fluid dynamic (CFD) modelling, especially for aeronautical flows with turbulence models of the $\kappa-\omega$ type, are very popular and represent a wide-open area for research [3]. It is well known however, that CFD cannot reproduce physics that are not properly included in the formulation of the problem, which is the case in the study of turbulence [3]. In more recent years Davidson [4] highlighted the apparent split in current turbulent studies into two distinctive groups. On one hand applied mathematicians focus on the origin of turbulence in a deterministic approach to quantify turbulence characteristics. Engineers on the other hand tend to focus solely on the likely affects of turbulence on an application whether structural or a process based.

The wind energy market is predominantly based on large wind turbines that are situated in non turbulent rural and off shore environments, These environments offer optimal conditions for energy extraction and being sparsely populated, these locations can readily accommodate larger capacity turbines. The macro wind energy context has resulted in a cautious but questionable approach when classifying turbulence and its likely effects in the boundary layer. Turbulence Intensity (TI) was proposed as a suitable means of quantify turbulence of dust particles based on a wind erosion model [5]. Following-on from this wind erosion model, studies on the statistical relevance as well as further empirical evidence were gathered. These studies ultimately led to a linking of the TI model to surface roughness parameters based on empirical experiments in wind tunnels [6]. Investigations linking TI and surface roughness tend to prioritise more thorough, a spatially distributed perspective on the time averaged mean and turbulent flow characteristics [7]. From wind engineering perspective, boundary layer physics has been employed to consider turbulence intensity with varying height within the boundary layer. Mertens [8] presented a model that scales TI in terms of the surface roughness length, $z_{0}$, but scaling in this regard is really only valid for wind energy systems located in rural environments.

There has been limited focus on the affects of power performance in the built environment where issues concerning planning and energy extraction in an associated turbulent wind resource present seemingly insurmountable challenges. From a resource evaluation perspective, site assesment using meteorlogical data has been shown to be a means of wind power prediction [9] while some researchers have employed proprietary software incorporating CFD [10]. The former requires 
specialised consideration in terms of the positioning of the metrological monitoring equipment, whereas the site specific nature of the latter means that an accurate and general means to assess the nature of the wind resource is difficult to establish. However, in the context of increased energy demand in cities, resulting from population migration [11] and the potential for smarter cities with smart network integration [12], there is an increased impetus for small wind energy systems in this regard. Currently nearly half of the world's population resides in cities and within two decades, it is envisaged this figure will rise to about $60 \%$ [11]. The need for demand centred generation with optimised transmission efficiencies creates the context for questioning what implications need to be addressed if wind generation technologies are to be optimally installed closer to urban centres.

From a wind energy system performance perspective, there is general acknoledgement that due to the rough and heterogeneous landscapes prevalent in urban environments that an increased level of turbulence will be manifested. It is also widely accepted that this increased level of turbulence will lead to a further degradation of turbine output. This paper will initially consider how this is not always the case, especially when quantifying turbulence by the current industrial standard Turbulence Intensity (TI). It also proposes that TI could be complimented by a further turbulence measurement $\mathrm{T}_{\mathrm{Df}}$ to enhance the site wind statistics to a higher quality. This statistical indicator $\left(\mathrm{T}_{\mathrm{Df}}\right)$ is compared to the classical TI indicator at two sites in Dublin Ireland. Following on from this the statistical effect of TI is examined in terms of power predictability estimation at the same two sites. The emphasis on the $\mathrm{T}_{\mathrm{Df}}$ model is postulated through the authors' ongoing investigations in the development of artificial time series that will facilitate the representation of wind energy system inertia.

\section{QUANTIFICATION OF TURBULENCE}

Increased prevalence of blind bluff bodies encountered in urban topographies escalates the erratic nature of wind velocities. This erraticism ultimately manifests an increased prevalence of turbulence, which has been shown to affect turbine performance both positively and negatively when measured using the Turbulence Intensity (TI) metric [13, 14].

$$
T . I .=\frac{\sigma_{u}}{\bar{u}}
$$

where $\sigma_{u}\left(\mathrm{~ms}^{-1}\right)$ is the standard deviation of wind speed over the sampling period (10 minutes) and $\bar{u}$ is the mean wind speed $\left(\mathrm{ms}^{-1}\right)$ over the sampling period.

However there are known limitations with the TI metric as a means to quantify turbulence in an urban environment. Firstly, the asymptotic nature of the metric as the mean wind speeds approach zero results in associated TI values that are greater than $100 \%$. Gusts are also more prevalent in an urban context and as a consequence, the standard deviation can be uncharacteristically high. Secondly the TI metric was adopted into the wind energy industry as a means to classify site conditions on wind farms where wind characteristics are relatively laminar in nature (with an associated lower standard deviation). Another underlying principle on which the TI model is based is that wind speeds are considered to be normal (Gaussian) in nature within the industrial standard 10 minute sampling period [15]. The authors have previously demonstrated that this not always the case and as an alternative proposed a methodology incorporating a dynamic Weibull Probability Density Function (PDF) [16]. This limitation of the Normal Turbulence Model (NTM) can be highlighted by considering a hypothetical but typical urban datum of a 10 minute averaged wind speed of $2 \mathrm{~m} / \mathrm{s}$ with a TI of $50 \%$. 


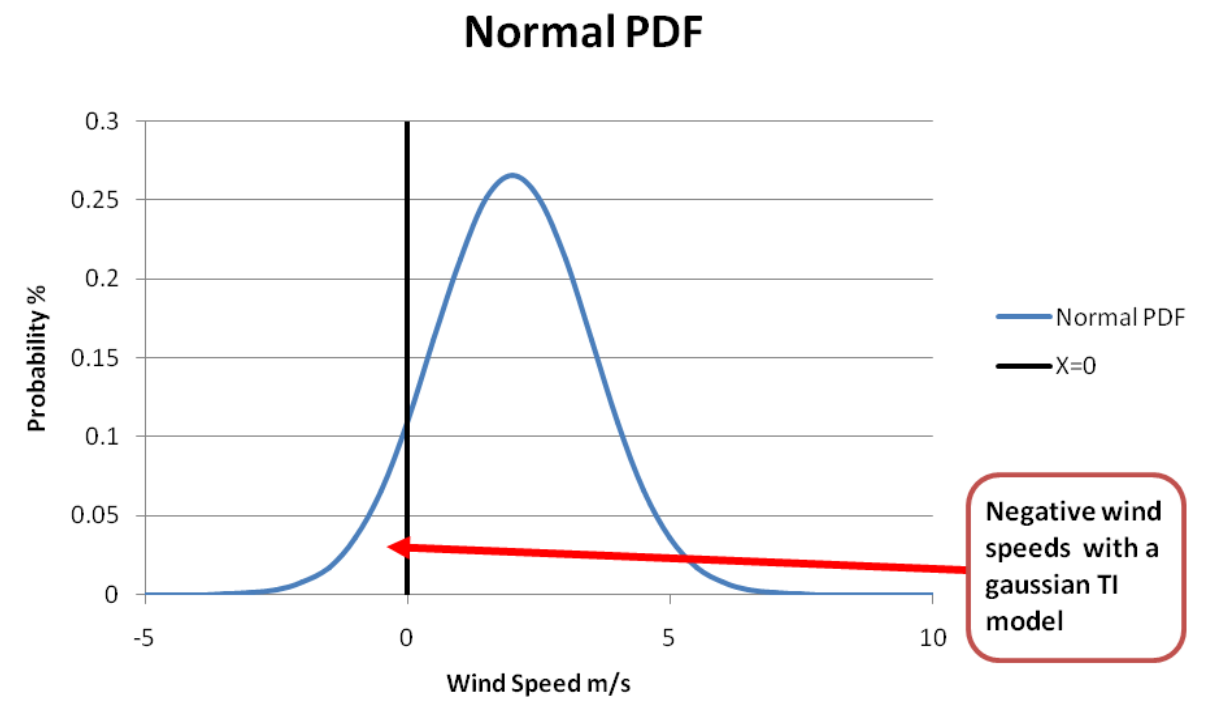

Figure 1 Normal PDF with mean of $2 \mathrm{~m} / \mathrm{s}$ and $\mathrm{TI}$ of $50 \%$

The (PDF) presented in Figure 1 illustrates this limitation as all wind models are based on speeds rather than velocities (i.e. negative speeds should not exist). Note also, if these negative wind speeds are truncated the standard deviation and TI values will change.

That said, this currently does not present an issue for the following reasons. Firstly wind turbines have cut in wind speeds that are predominantly greater than $3 \mathrm{~ms}^{-1}$. Therefore any power that is generated below a 10 minute average wind speed of $3 \mathrm{~ms}^{-1}$ is negligible in respect to the yearly output for most sites. Secondly where these wind speeds are lower and more erratic, such as within the urban context, there are only a limited number of installations currently installed. The consequences therefore result in an inability to predict power performance accurately therein. This has led to the development of a new mathematical model for measuring turbulence called the Turbulent Fourier Dimension $\mathrm{T}_{\mathrm{Df}}[17,18]$.

\subsection{Field Measurements}

Observations are made at two sites in the Dublin city area using a CSAT3 three-dimensional sonic anemometer [19]. Measurements were taken consistently from 4/4/2012 to $15 / 5 / 2012$ at both locations at a frequency of $10 \mathrm{~Hz}$ with an associated resolution-between $0.5-1.0 \mathrm{mms}^{-1}$, with data including date and timestamp and wind-speed using Cartesian coordinates $\left(\mathrm{u}_{\mathrm{x}}, \mathrm{u}_{\mathrm{y}}, \mathrm{u}_{\mathrm{z}}\right)$. These can then be resolved to provide wind speed, wind direction and standard deviation for any given sample size. Site 1 (URB 1) is characterised by mixed building morphologies containing low and high rise developments at Marrowbone Lane, located in Dublin 8 (53 $\left.20^{\circ} 15.96^{\prime}{ }^{\prime} \mathrm{N}, 6^{\circ} 17^{\prime} 10.27^{\prime \prime} \mathrm{W}\right)$. Site 2 (SUB 2) is characterised by low rise developments with increasing amounts of similar height vegetation. The anemometry is installed at St. Pius X National (Girls) School, located in Terenure,

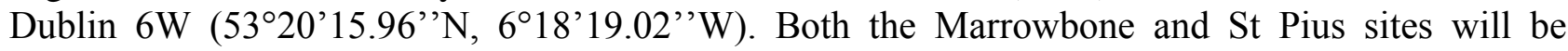
hereafter referred to as $U R B 1$ and $S U B 2$ respectively. 

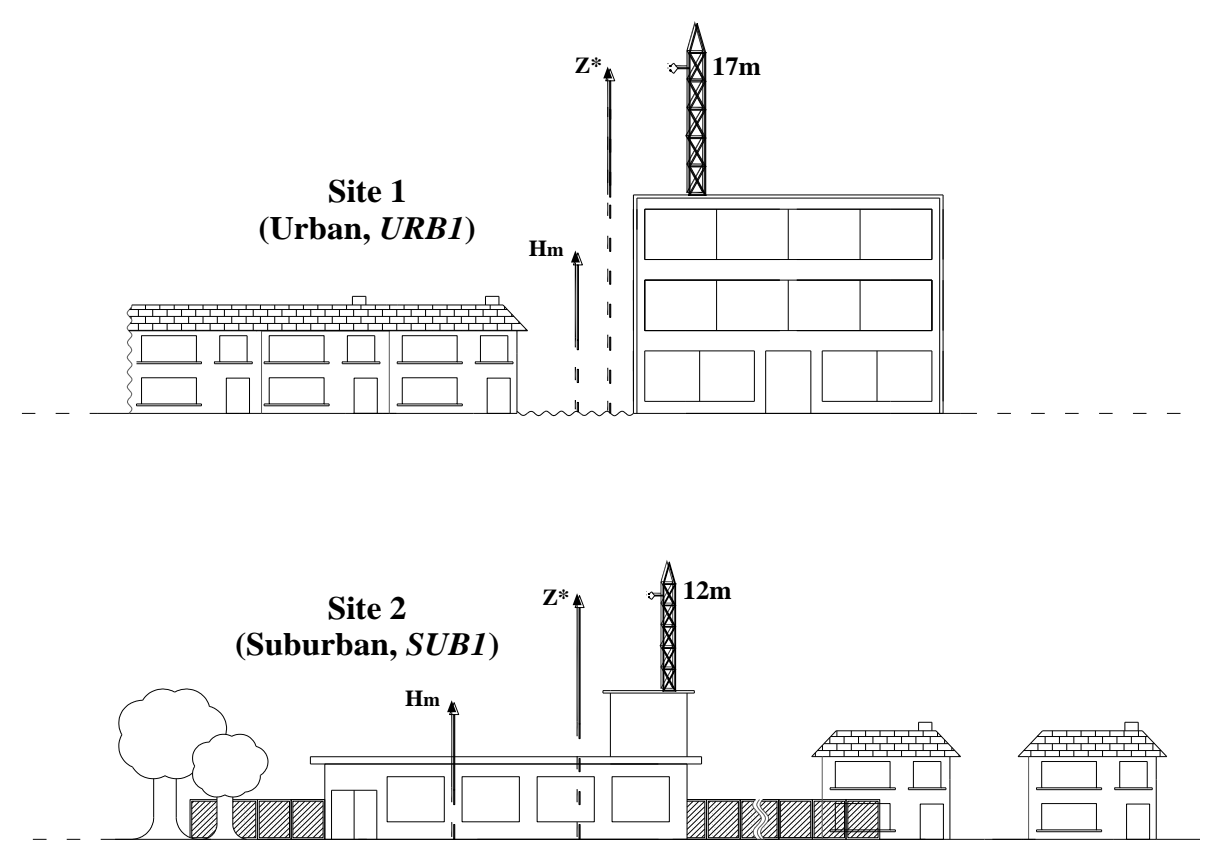

Figure 2: Indicative environmental context of wind observation locations.

\subsection{Turbulence Intensity (TI)}

In the analyses presented here, longitudinal turbulence intensity is prioritised, and specifically uses the horizontal component of the wind speeds $\left(\mathrm{u}_{\mathrm{x}}, \mathrm{u}_{\mathrm{y}}\right)$, cosine corrected over a 10 minute sequential window. This correction was calculated in accordance with IEC 61400-2 [20] which is the generally accepted industrial standard and therefore suitable as a benchmark for $\mathrm{T}_{\mathrm{Df}}$.

\subsection{Turbulent Fourier Dimension $\left(\mathrm{T}_{\mathrm{Df}}\right)$}

Fractal models have long been associated with non Euclidean dimensions that are ever present in the natural world [21]. In recent years this fractal theory has been extended to be encompassed as a section within the noise spectrum and as such can be loosely extended into noise theory [22, 23]. It should be noted however that strictly speaking fractal theory limits the Fractal Dimension (Df) between the limits of 1 and 2 . The $T_{\mathrm{Df}}$ is effectively the same measurement but not bounded by the limits of fractal theory.

If we consider a uniform spread of random numbers $\left(\mathrm{n}_{\mathrm{x}}\right)$ between [0-1] subjected to the following convolution;

$$
\left[u_{x}(t)\right]=\frac{1}{t^{1-q / 2}} \otimes \mathrm{t}\left[n_{x}(t)\right]
$$

where: $\mathrm{T}_{\mathrm{Df}}($ Turbulent Fourier Dimension $)=(5-\mathrm{q}) / 2$

Frequency domain equivalent with $i$ indexing filter

$$
\left[U_{x}(\omega)\right]=\frac{1}{(i \omega)^{q / 2}}\left[n_{x}(\omega)\right]
$$



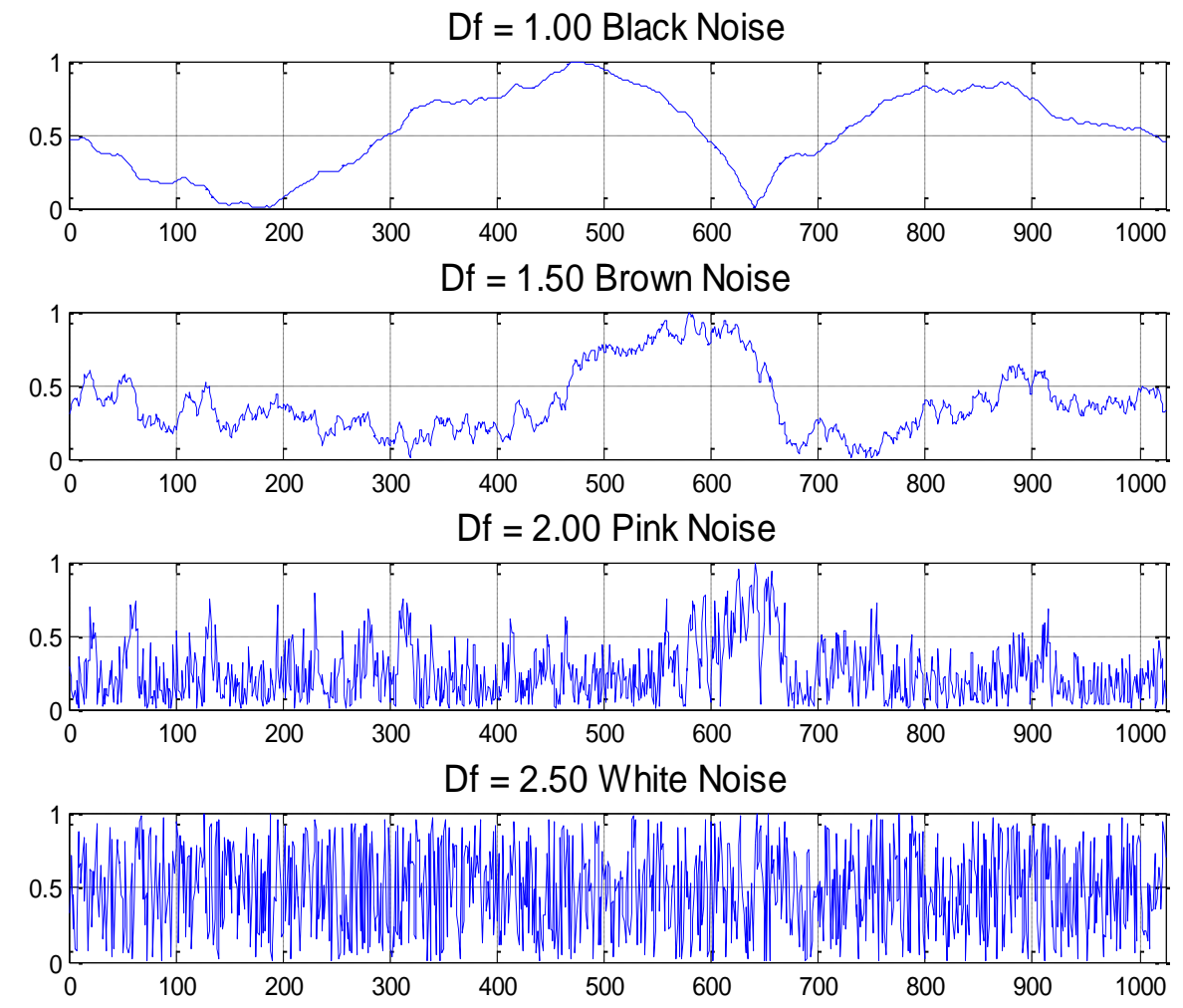

Figure 3: Synthetic noise signals of 1024 random numbers with known Df

Effectively $\mathrm{T}_{\mathrm{Df}}$ quantifies a value of self symmetry within a signal; the more self symmetry that is present within a wind speed signal, the higher the quantified noise content, which also implies a higher turbulent content. For brevity, the $\mathrm{T}_{\mathrm{Df}}$ is calculated as follows with further details laid out in [18].

The Fast Fourier Transform (fft) was applied to each 10 minute bin of $10 \mathrm{~Hz}$ wind data (6000 entries of horizontal wind speed). Only terms from $\mathrm{n}(2)$ to term $\mathrm{n} / 2$ are considered (Note; the DC component, $\mathrm{n}(1)$, as the average wind speed was removed. The optical form of the power spectrum is symmetrical and as a result only terms up to $n / 2$ are considered.)

Consider the visual representation of the power spectrum of a fractal expression. If such a power spectrum is subjected to a $\log \log$ transformation (i.e acquiring the $\log$ of both axes), the resultant line will have a slope componant $(m)$ that is indicative of the quantity of scale invarient self symmetry in the original time series signal.This slope is synonymous, in this instance, with the spectral exponant of the fourier dimension $q$ illustrated in (3). The following formula is then applied to determine the fractal dimension by fourier means in accordance with [23].

$$
T_{D f}=\frac{(5-q)}{2}
$$

In order to obtain a like for like comparison with the TI metric, the cosine corrected horizontal component $\left(\mathrm{u}_{\mathrm{x}}, \mathrm{u}_{\mathrm{y}}\right)$ wind speeds over a 10 minute sequential window were employed in both the $\mathrm{T}_{\mathrm{Df}}$ and TI calculation.

\subsection{Comparative Results}

As both metrics have a scaling factor that is dependent on mean wind speed, it is necessary to bin all calculated turbulence values based on mean wind speed over the 10 minute interval. For this 
reason holistic averaging of $\mathrm{TI}$ and $\mathrm{T}_{\mathrm{Df}}$ values are avoided as they can be misleading and problematic when comparing similar sites.

It is evident in Figure 4 that the TI metric is inconclusive as to which site is more turbulent over a turbine's operating wind speed spectrum (in general between $3 \mathrm{~ms}^{-1}-25 \mathrm{~ms}^{-1}$ for small scale turbines $(<6 \mathrm{~kW}))$.

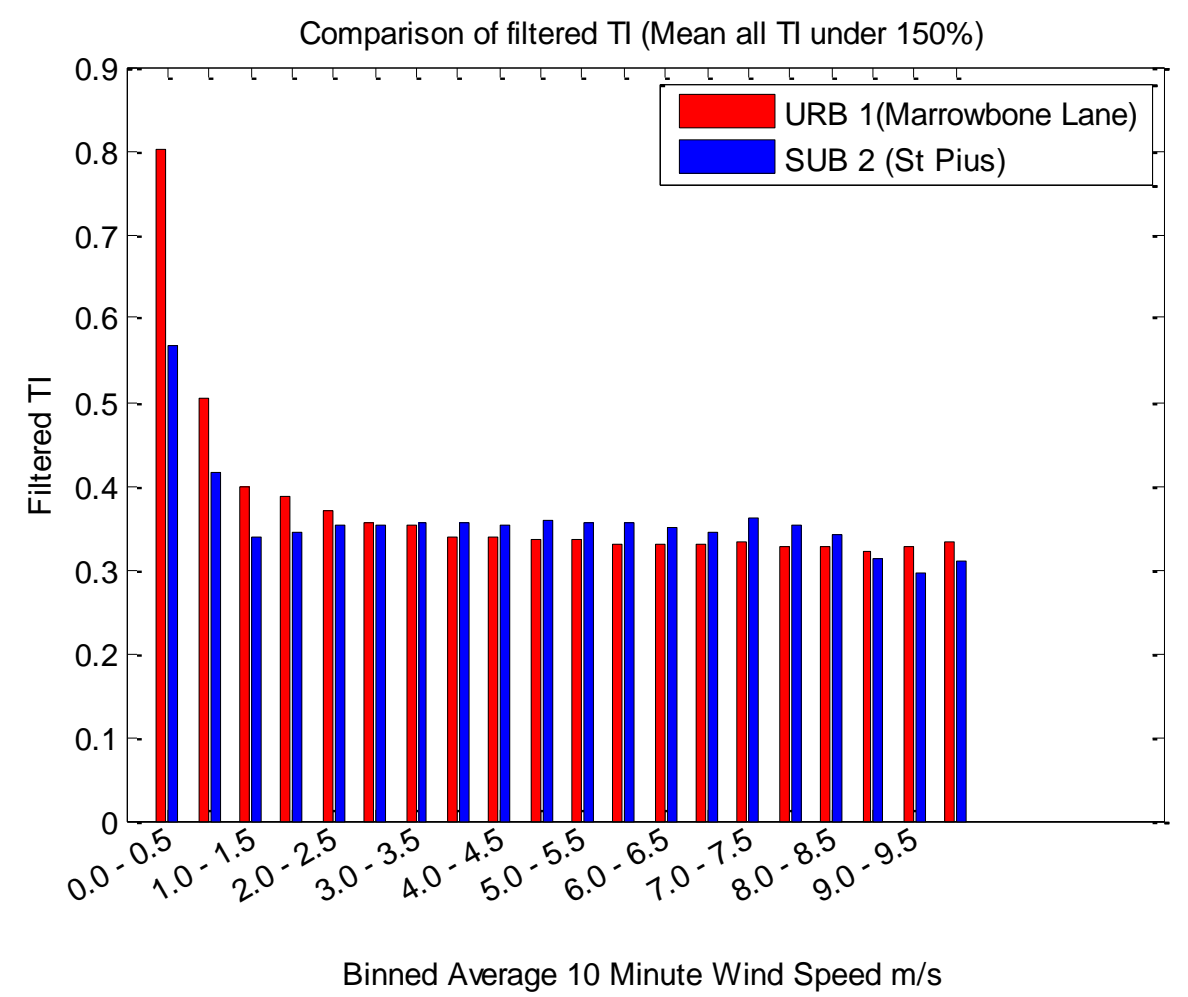

Figure 4 Mean Filtered TI for both sites with a class width of $0.5 \mathrm{~m} / \mathrm{s}$.

With regard to the TI metric the URB 1 site is more turbulent at low wind speeds. It should be noted however, that such extreme low wind speeds with wind speeds less than $2.5 \mathrm{~ms}^{-1}$ account for a sizable portion of the entire data set (circa $25 \%$ of the entire sample). Figure 4 also implies that SUB 2 is more turbulent from $3-8.5 \mathrm{~ms}^{-1}$. (Note: these are representative of typical operational wind speeds for micro wind turbines). Figure 5 depicts the $\mathrm{T}_{\mathrm{Df}}$ for the same data set. The $\mathrm{T}_{\mathrm{Df}}$ model gives a clear indication that URB 1 (Marrowbone) is more turbulent than SUB 2 (St Pius). 


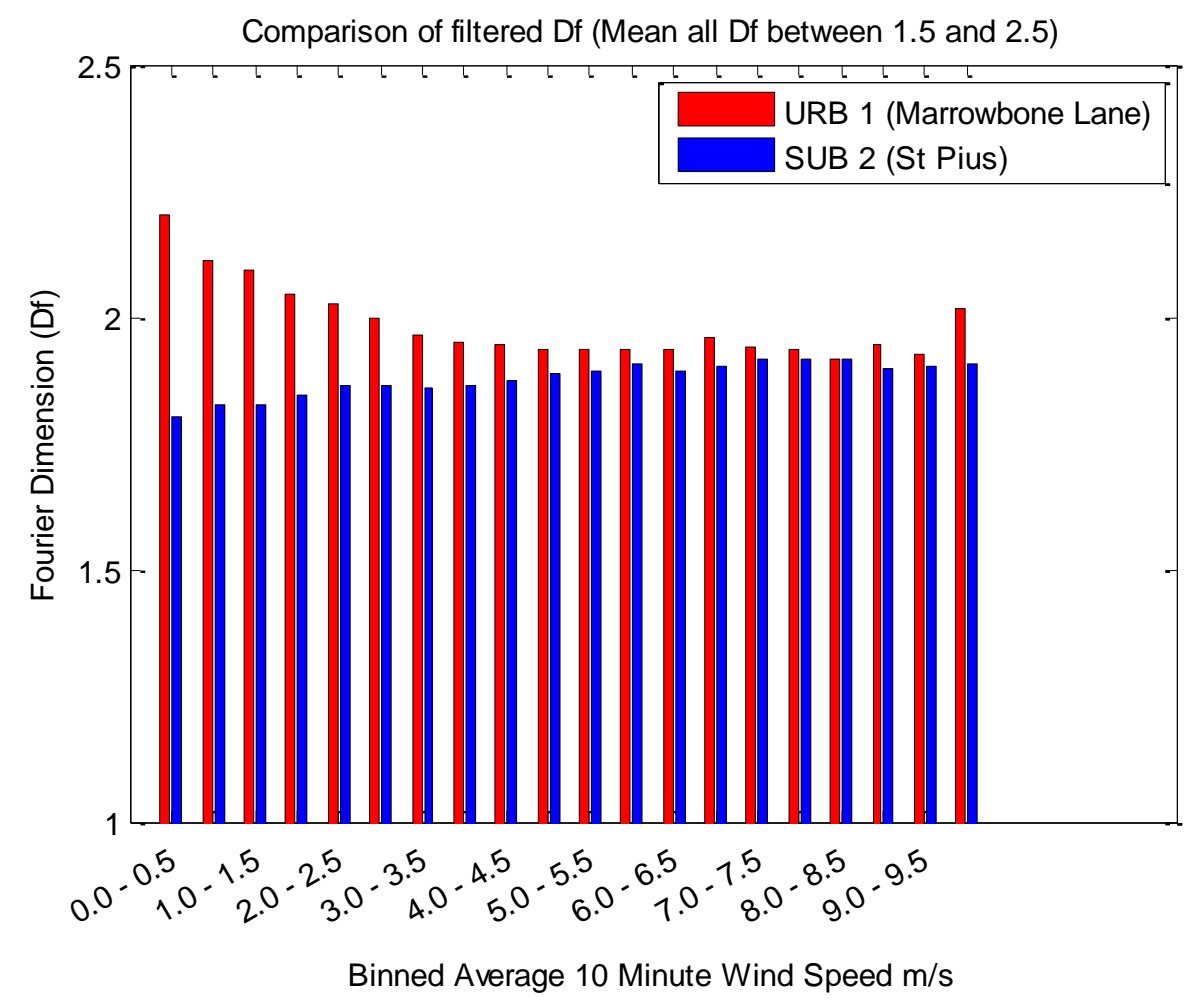

Figure 5 Mean Filtered Df for both sites with a class width of 0.5 units.

The results presented in Figure 5 suggest that the $T_{D f}$ model represents a more definitive means for turbulence classification for a given site. However The TI model is currently the only benchmark with the ability to influence power prediction. The next section is a synopsis of some of the authors previous work in this area [16].

\section{POWER PREDICTION BASED ON TI}

Turbulence has been shown to have an effect on the wind turbine characteristic. Field trials by Lubitz [24] as well as correlation techniques by Langreder [13] (see Figure 6) have illustrated this point. The research undertaken by both Lubitz and Langreder concluded that turbulence has positive effects at low wind speeds and negative effects at higher wind speeds.

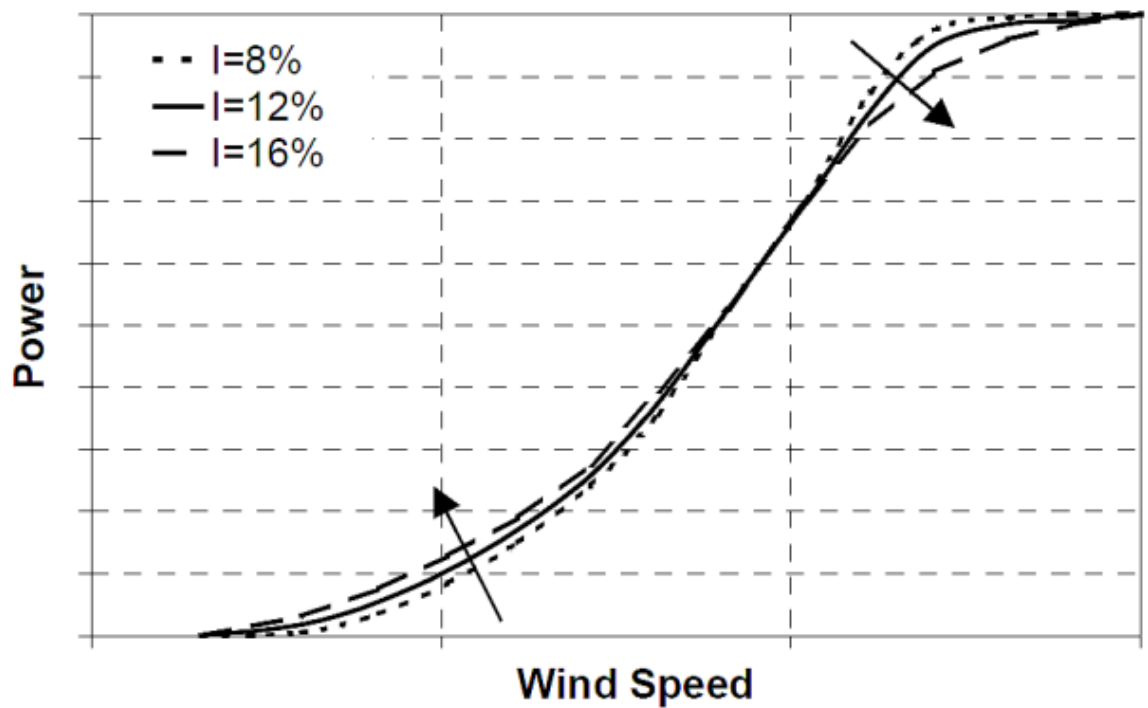

Figure 6 Typical Effects of Turbulence on Power Curves [13] 
In recent years tentative steps have been made towards a generic means of predicting the effects of turbulence on a turbine characteristic with respect to modelling the power performance of microturbines in turbulent environments. Albers [25] provides a means and justification of normalising the turbine characteristic for site specific measurements of TI.

This method if slightly amended has the ability to generate a power curve for a given turbine at any given TI value. The following steps can be made in order in order to generate power curves for a known turbine at various TI values.

1. The manufacturer's power characteristic for the given turbine is obtained. (Note: this is an average turbine power taken from manufacturers test data),

2. Break up the wind speed into suitable sized datums (typically $0.1 \mathrm{~m} / \mathrm{s}$ ),

3. Generate a normal PDF for each of these datums using the datum as the average wind speed and the standard deviation, $\sigma=\{T I \times$ (wind speed datum) $\} \quad$ (Note a large number of samples is required for an accurate result, typically 6000, which equates to 10 minutes of data at a sampling frequency of $10 \mathrm{~Hz}$ ),

4. For each of the 6000 generated wind speeds quantify the power based on the manufacturer's power curve. Note values outside of the working range need to be forced to 0 prior to averaging.

Figure 7 demonstrates how this approach can be used as a means to generate a power curves for all values of TI for a Skystream $2.5 \mathrm{~kW}$ turbine.

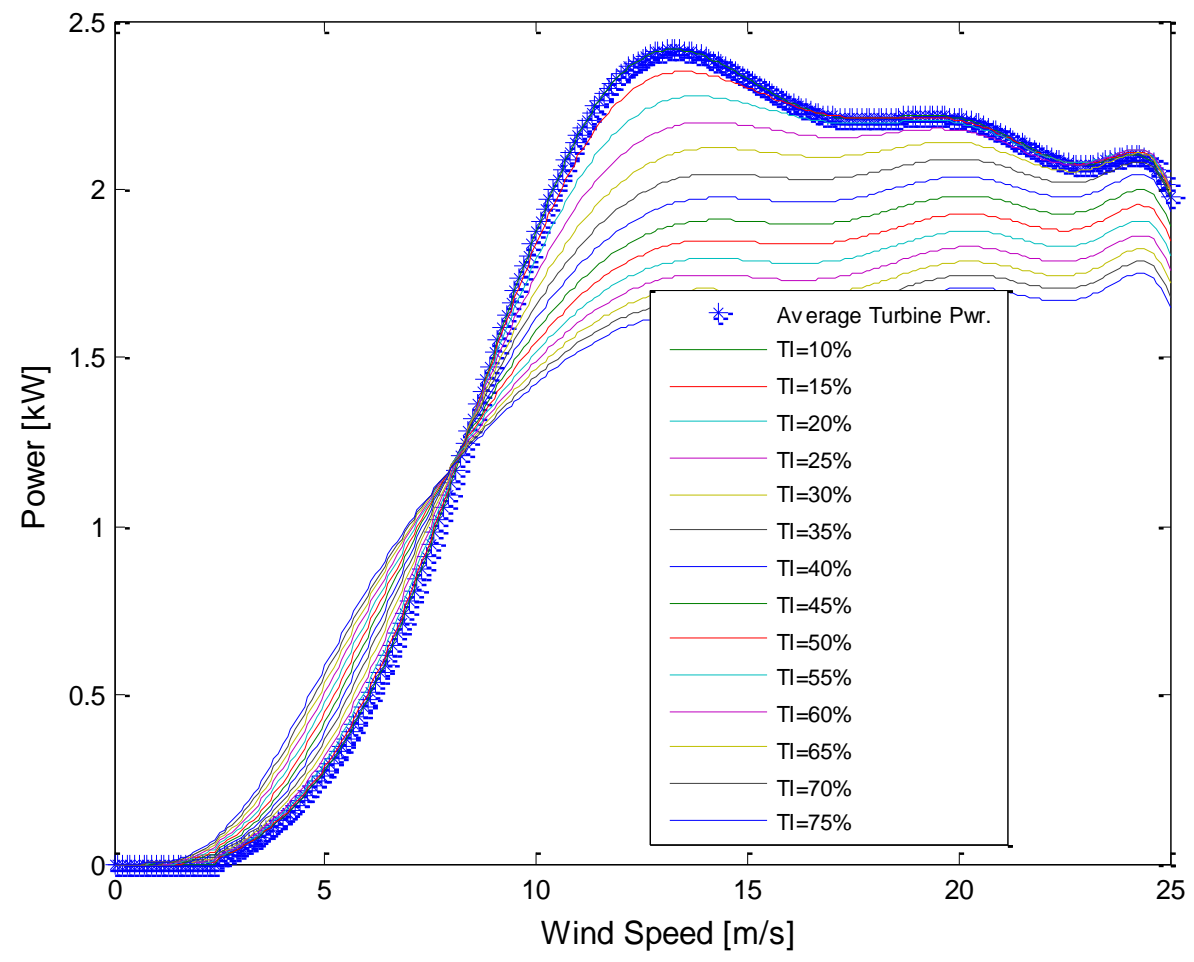

Figure 7 Alber's approximation of power curve based on varying $\mathrm{TI}$

It should be noted that this mathematical approach is consistent with observations in the field studies by Lubitz and Langreder [13, 24]. Another interesting consideration concerns the manufacturer's data and how it is derived. Most manufacturers base their power curves on averaged field test data from generic site conditions in accordance with [20]. As these sites are subjected to some turbulence Albers argues that this may need to be compensated for in the calculation. 
However as the TI data of the test conditions are rarely published, it is unlikely that an accurate answer can be formulated. If on the other hand we assume that the test sites are selected on the basis of being a low turbulence environment a compensating TI of between $10 \%$ and $20 \%$ would appear to be suitable for the vast majority of low turbulence test sites.

It should be noted that due to the frequency dependant nature of this power prediction model that the response time of the turbine cannot be included in the calculation. This model therefore assumes an instantaneous response rate is achievable by the turbine system for every change in wind speed. It could be argued that for small turbines that the response time is relatively small but the same cannot be said for larger turbines due to the effect of mechanical inertia.

\subsection{Self Validation Procedure}

As a form of self validation of the power predictability approach three powers were calculated and compared based on the following procedures.

In the first Instance the absolute power was calculated using the raw data $(10 \mathrm{~Hz})$ and a bounded polynomial as presented in Figure 8. This was used as a benchmark as this is the only power that is calculated on the basis of the raw data.

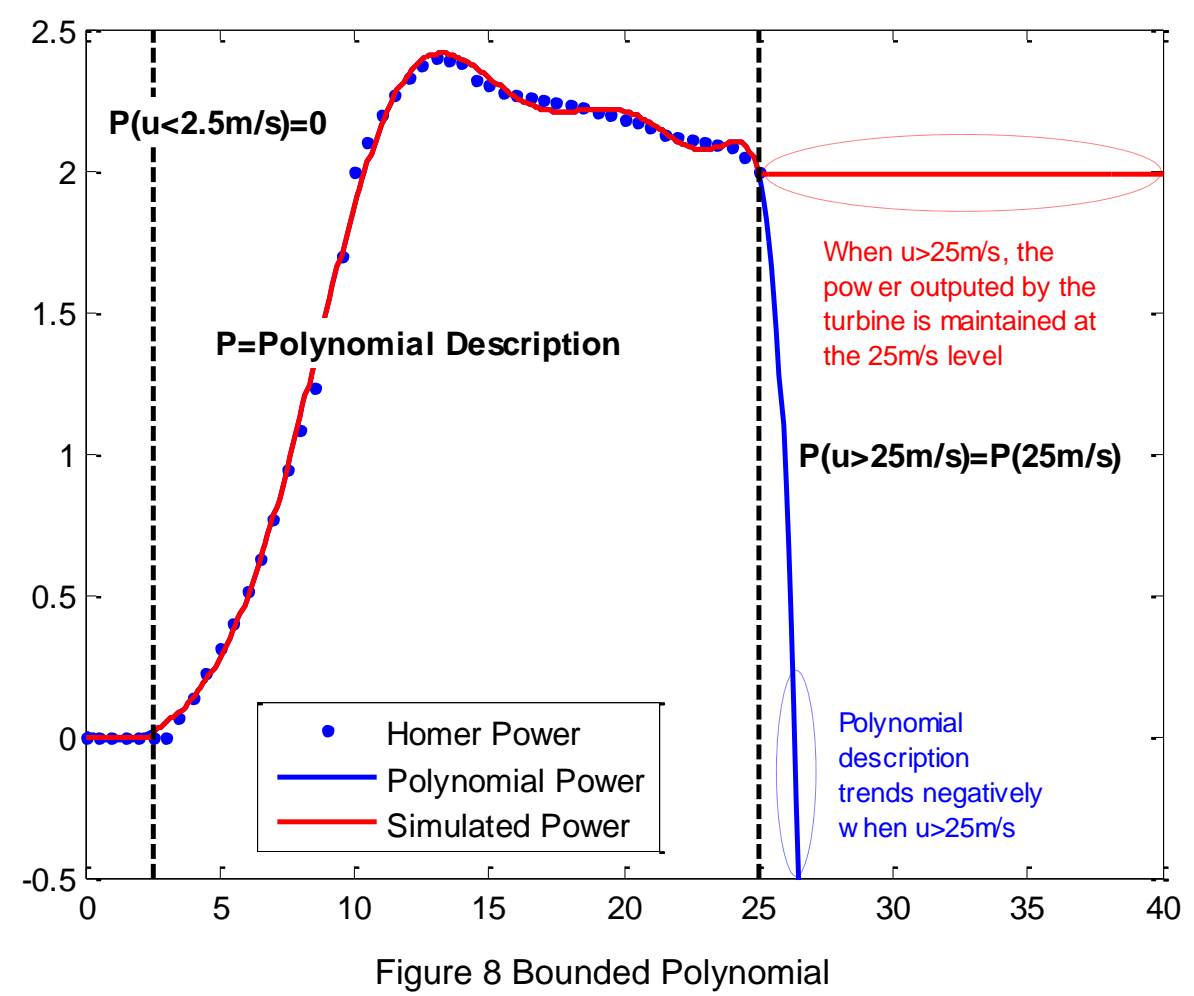

Secondly the mean power (Pmean) was calculated using the industry standard 10 minute mean (i.e. mean wind speed considered but no allowance for TI). Once again power is calculated using the polynomial method illustrated above.

Finally the TI normalised power (Pnorm) is calculated based on the TI values influencing the power curve so that an altered resultant power output is obtained.

\subsection{Comparative Results}

The two simulated turbine output powers (Pmean and Pnorm) were benchmarked against the raw data power (Pabs). 
The cumulative error for both sites (URB1 and SUB 2) indicates that virtually all $(>99 \%)$ of all simulated Pnorm results are within $+/-50 \mathrm{~W}$ of the Pabs value. To put this into context the Skystream is a $2.5 \mathrm{~kW}$ turbine so $>99 \%$ of all simulated Pnorm values lie within a $2 \%$ error.

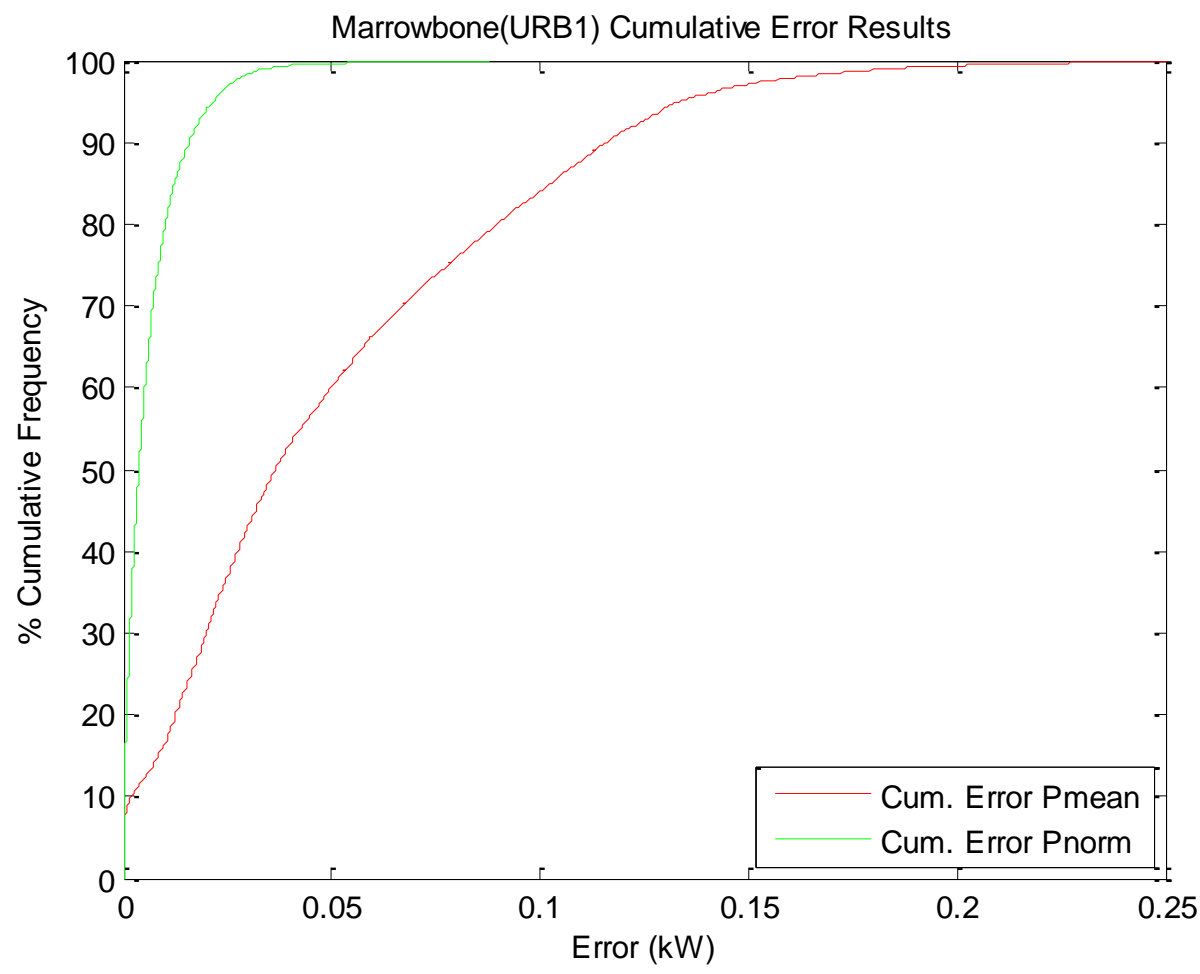

Figure 9 Cumulative error from Pmean and Pnorm prediction methods benchmarked against Pabs for Marrowbone (URB1)

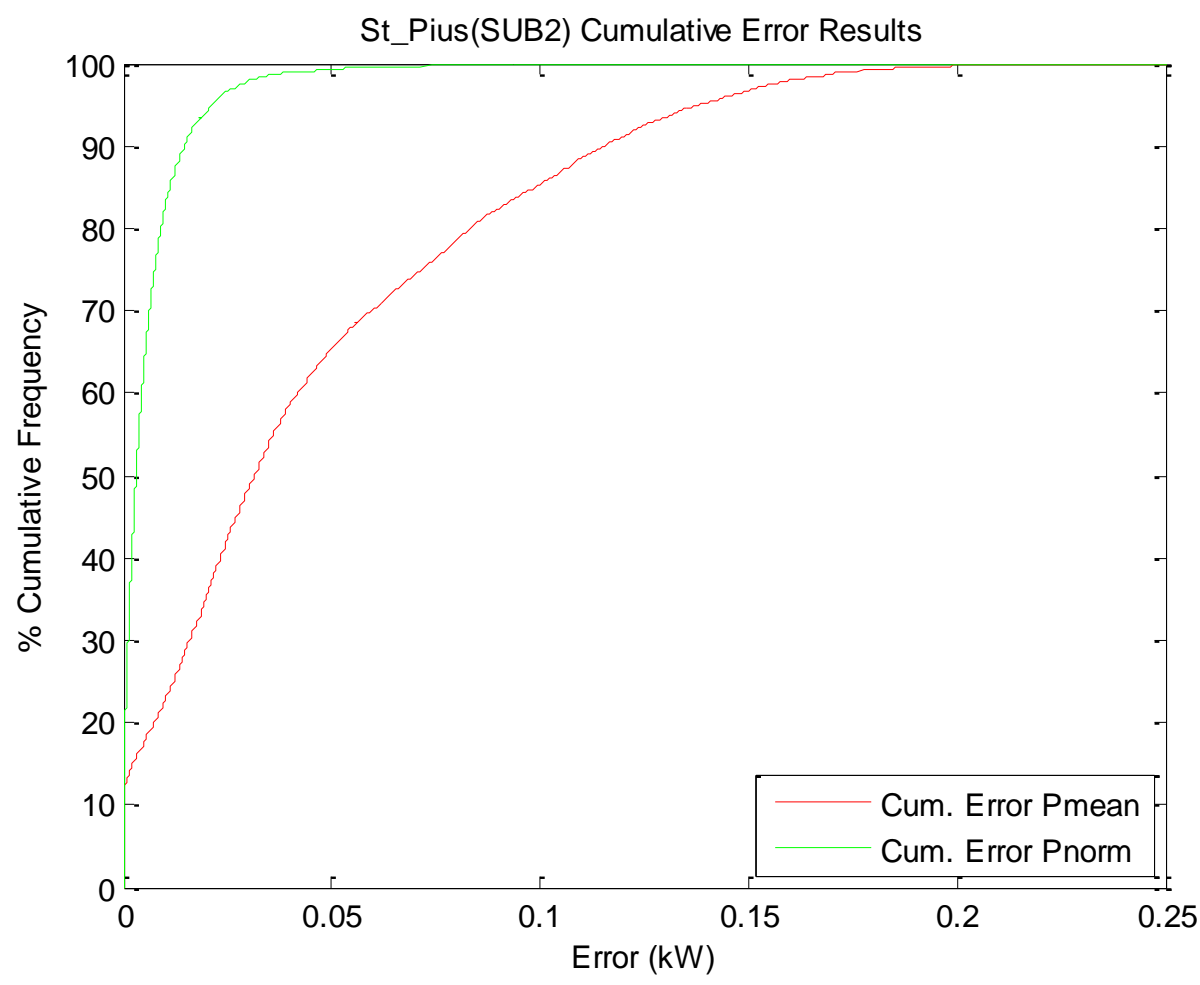

Figure 10 Cumulative error from Pmean and Pnorm prediction methods benchmarked against Pabs for St Pius (SUB2) 
This is in sharp contrast with the current industrial standard which is the Pmean based on the manufacturers power curve and the average wind speed over a 10 minute period. While the cumulative error is drastically reduced with this method it also has the ability to consistently under predict for the given scenarios as illustrated by Figures (11-12). This would infer that this method is statistically accurate ( $>97 \%$ of all recordings are within $2 \%$ of the rated power of the turbine). However it does not take any cognisance of any response rate of the turbine or indeed any power loss associated with yawing. This has led to the development of a system response model that is currently being developed by the authors and a brief introduction to its concept is given in the next section.

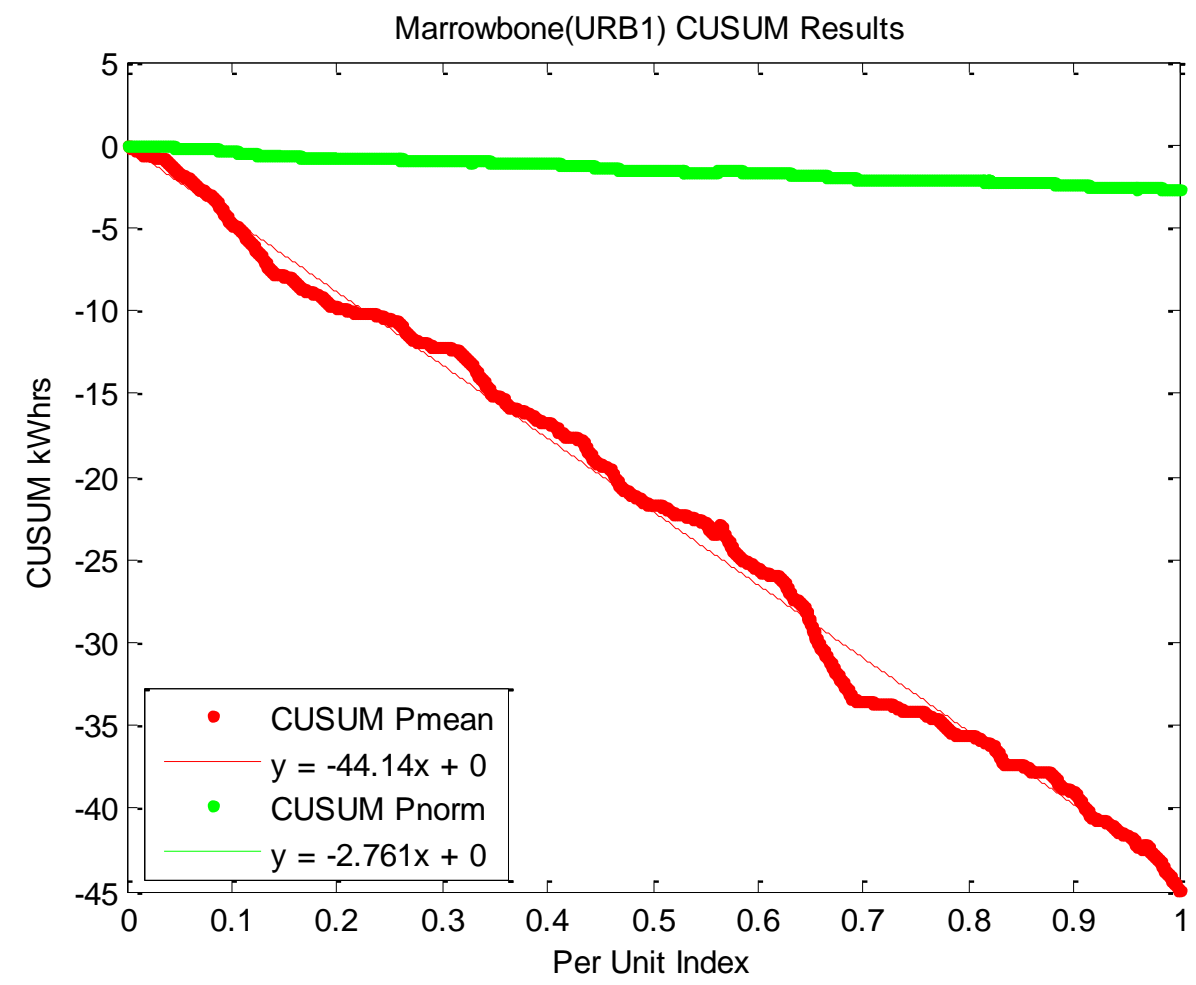

Figure 11 CUSUM analysis based on Pmean and Pnorm using Pabs as a reference for Marrowbone (URB1) 


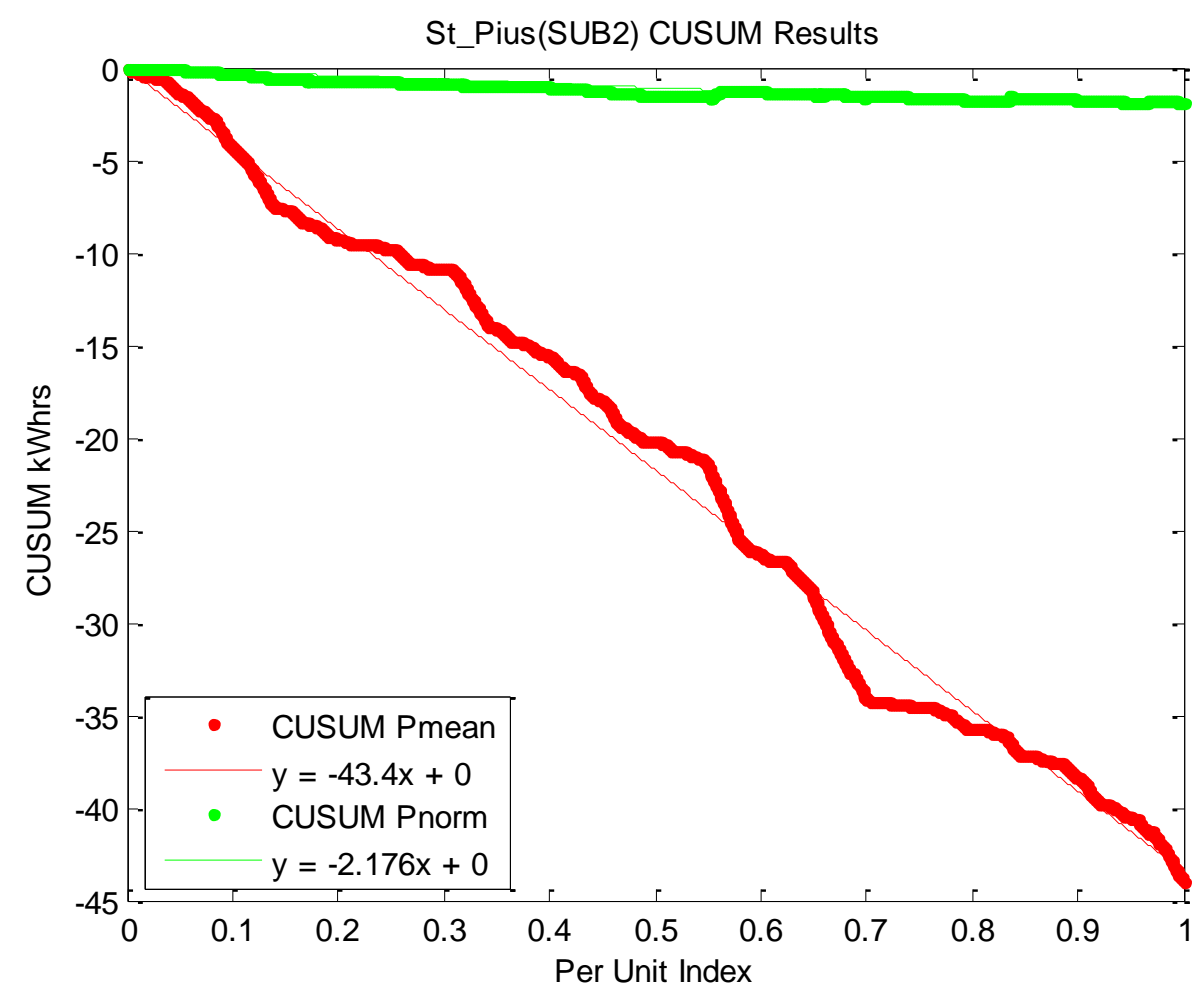

Figure 12 CUSUM analysis based on Pmean and Pnorm using Pabs as a reference for St Pius (SUB 2)

\section{ONGOING WORK}

\subsection{SWEET Modelling}

Recently the authors have also developed a more user friendly turbulence prediction model for micro wind turbines.

The SWEET (ver 1.1) model has been developed based on an approximation of the Albers (Pnorm) approach described earlier in section 3. It is intended that this model will eventually be embedded into a full software program so as to facilitate a holistic power prediction application for micro turbines pre- installation. A copy of the Small Wind Energy Estimation Tool can be downloaded at http://arrow.dit.ie/engschelecon/8/ and a synopsis of its functionality is provided in Appendix A-1.

\subsection{Accommodating the system inertia into the turbulence model}

The $\mathrm{T}_{\mathrm{Df}}$ model presented in 2.3 provides an alternative means of turbulence classification i.e. as a complimentary statistical marker to the current industrial accepted model with TI and mean wind speed in a Normal Turbulence Model (NTM) [1]. The $\mathrm{T}_{\mathrm{Df}}$ model currently does not however, facilitate any form of power prediction capability. A likely and considerable contribution such a model could have however, is an ability to include related system inertia reaction time or as time constants of the wind generation system as a whole. Such a calculation could take the response time of the generation system as a whole into consideration. For example if a turbine had the ability to go from $50 \%$ output to $70 \%$ output in 4 seconds a suitable growth / decay curve could be implemented for a more accurate time domain response rate for a given turbine cognisant of the turbulent wind environment. The model currently being developed is based on a natural transient growth / decay model based on an input response function for a change in velocity. There are three major challenges with the development of this model.

1. There is an assumption that the response of the system is based on a natural growth/decay with an associated time constant $\tau$. There currently is no empirical 
evidence to support this, so in the absence of any alternative, exponential growth/decay in the representation of the system response is assumed.

2. $\tau$ is currently not defined in manufacturers data and as such needs to be quantified for a given turbine.

3. The volume of data storage required to undertake time series modelling is considerably larger (A singular datum for a 10 minute window could be replaced with $1 \mathrm{~Hz}$ data for the same period of similar unit accuracy would increase the storage requirements by a factor of 600 ).

Notwithstanding these concerns, consider system inertia response as a function of wind speed variation as presented in Figure 13. Here a real world wind speed scenario for a varying $\tau$, is presented. Intuitively it is predicted that smaller turbines $<3 \mathrm{~kW}$ would have a much rapider system response possibly down as low as $1 s$ and due to the larger mechanical inertia of the larger turbines the response would be slower and hence less capable of effective generation in a highly turbulent environment.

Another advantage of this method is that the time constant $\tau$ is defined as a response rate of the input function $u$. In essence the calculation defines a new $u$ for a given response rate. This allows the calculation to be all encompassing of all turbine components without having to be cognisant of response rates of all component parts (e.g. rotor pick up/inertia / rotor yaw response / gearbox response / generator response / microelectronics response etc.).

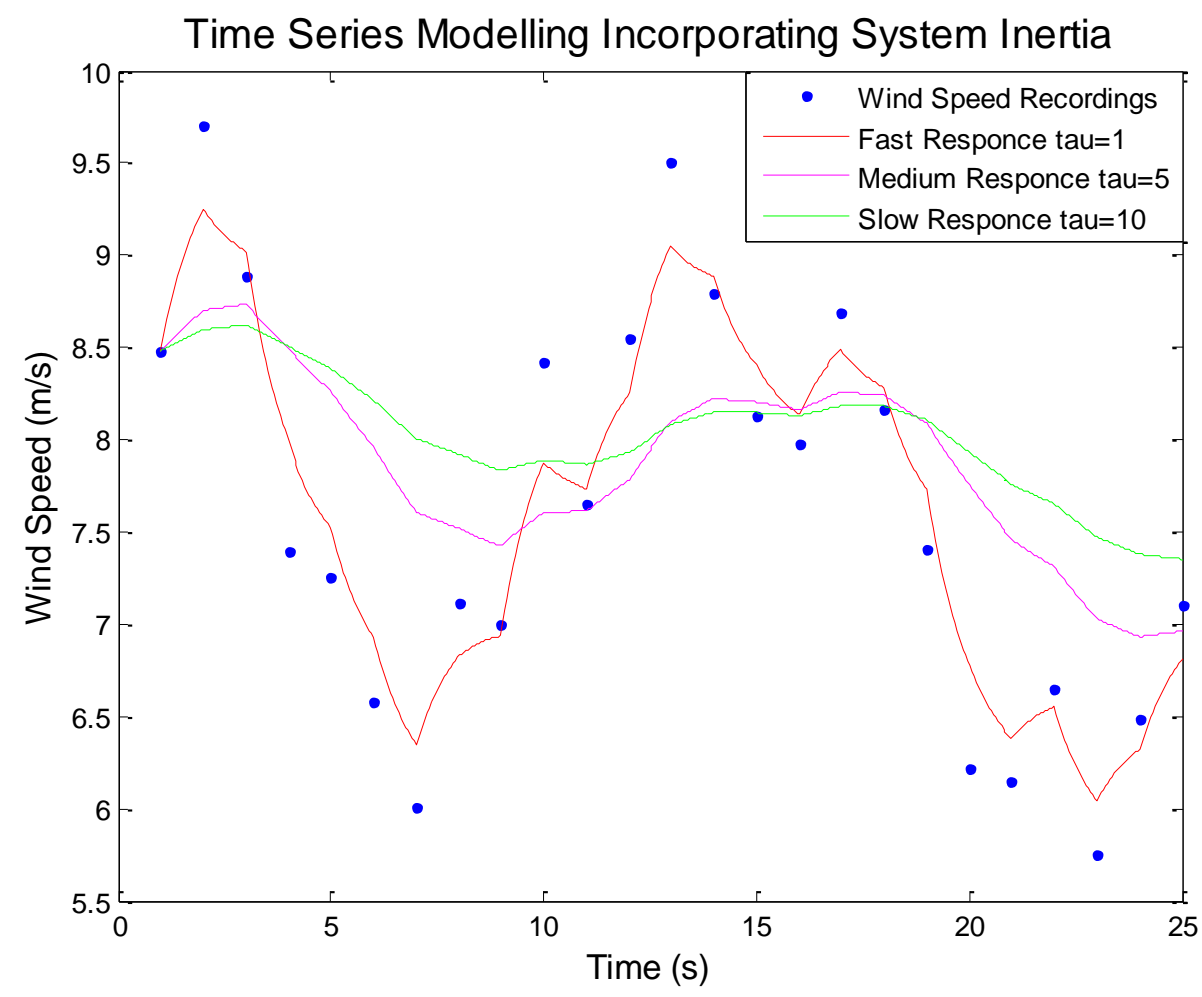

Figure 13 Various system response capabilities based on varying $\tau$.

\subsection{Statistical Model Development}

In consideration of Figure 13, it is clear that more development needs to be made in encompassing all statistical markers whether classical Gaussian or non Gaussian fractal into a holistic model if the effect of system response in a turbulent environment on a turbine is to be achieved. Such achievement will be predicated on a more holistic appreciation of how these markers are integrated within the wind speed signal. Ongoing work in this area is in the development of artificial wind 
signals based on 3 statistical markers (mean, $\mathrm{SD}, \mathrm{T}_{\mathrm{Df}}$ ) and then comparing this synthetic wind speed with the recorded real wind speed from which the statistical quantities were originally derived. Currently a wind signal is generated as a defined noise signal by means of $\mathrm{T}_{\mathrm{Df}}$ which is then stretched to a suitable standard deviation (SD). This is then scaled to a suitable mean in order to get a more indicative artificial time signal within the time domain for calculation purposes. However this would involve the recording of the $\mathrm{T}_{\mathrm{Df}}$ parameter within current logging technology.

The work in this area is at an incipient stage and as such there is no data to date. The proposed methodology is postulated on the basis of an inability of a frequency domain model to compensate growth / decay curves on consecutive wind speed datums.

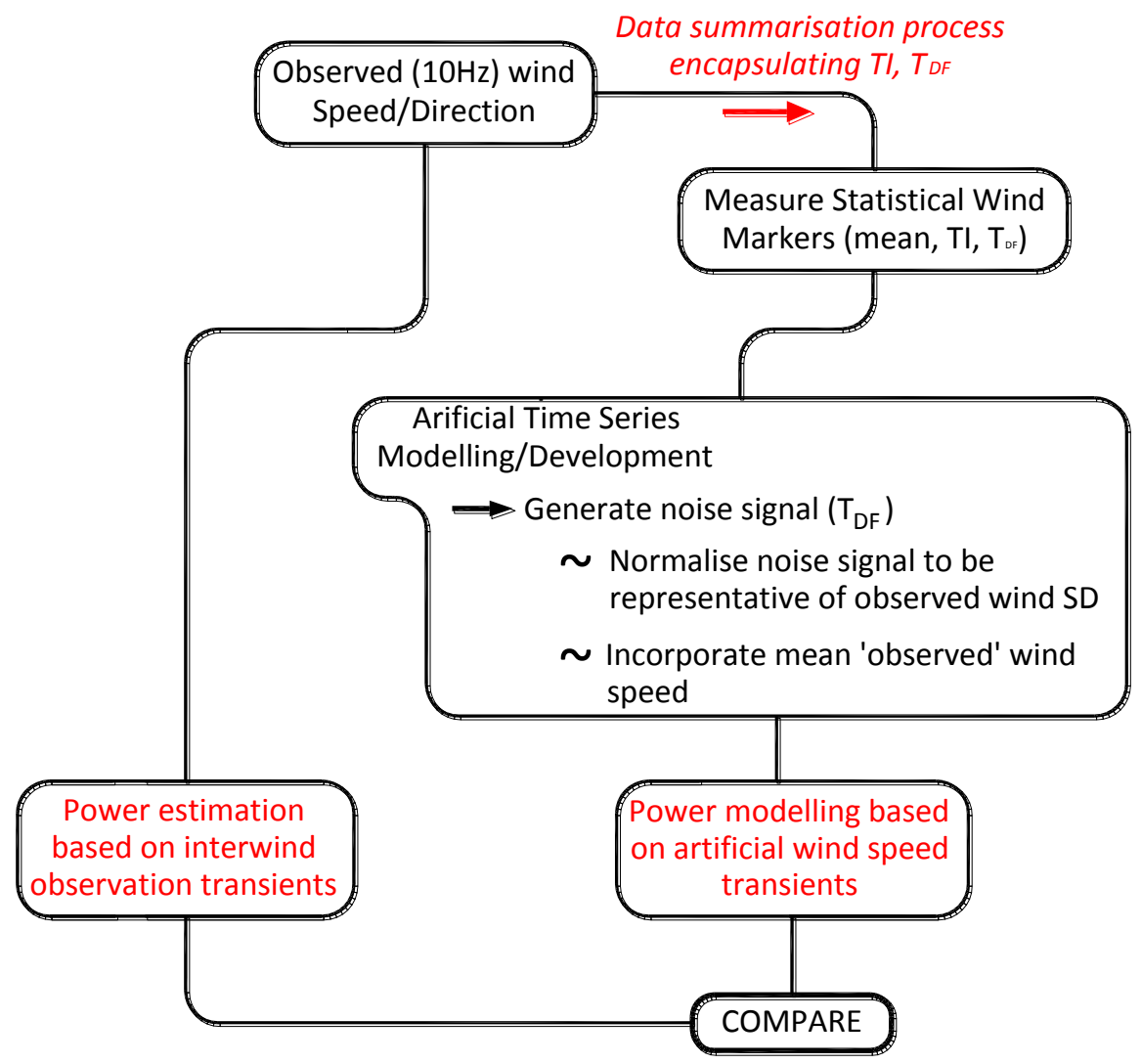

Figure 14 Proposed Methodology for Artificial Wind Speed Comparison

Figure 14 outlines the proposed approach for the development of the statistical development of the system inertia model. The test model (in this instance a time series model incorporating system inertia) will employ statistics as a means of data summarisation similar to that of a data logger. An artificial time series, created from these same statistics will then be applied to give an indicative artificial wind speed. The time series model algorithm will then be applied to both the real world and artificial data. This approach will provide for a comparative benchmark, i.e. the real world scenario, to which the artificial model can be cross referenced for a range of scenarios of $\mathrm{T}_{\mathrm{Df}}$, mean, and TI.

The ability to compress data while still maintaining some time series intervariability is a promising development. Ultimately this model if validated through field studies could be adopted as an alternative data summarisation and power prediction model for all types of turbine installation in both laminar and turbulent environments. 


\subsection{Turbulence Rose}

While cities generally are characterised as having a slightly unstable climate, with respect to the Irish climate, there is a propensity for the climate in Dublin to be neutral i.e. conditions where buoyancy, which is sensitive to temperature stratification, is less influential and cloudy skies and strong winds are prevalent [26]. Cloud reduces radiative heating in this regard and cooling of the surface with strong winds promoting mixing without strong temperature stratification turbulence in a neutrally buoyant climate tends to be predominantly influenced by wind negotiating real world objects thereby changing direction and wind speed. It is therefore highly likely that urban complexities in a given direction will result in increased measurement of turbulence in that given direction. This concept is being explored at both sites (URB1 and SUB) but as Figure 15 illustrates, with regard to 30 degree wind direction segments, the average TI within these segments does not explicitly define any direction as being the most dominant from a turbulence manifestation perspective. However, as both the meteorological equipment is installed at specific locations in which the surrounding geography is relatively homogenous and consistent for the locations specified, turbulence roses in this regard should be consistent.

An additional site has been selected (on the roof of Dublin Institute of Technology) at which the meteorological equipment is situated at a junction between two entirely different surface form classifications, i.e. highly urban and almost suburban. The intention is to investigate if, at this location, directionally calculated TI will show increased $\mathrm{T}_{\mathrm{Df}}$ or TI e.g. an upstream obstruction etc.

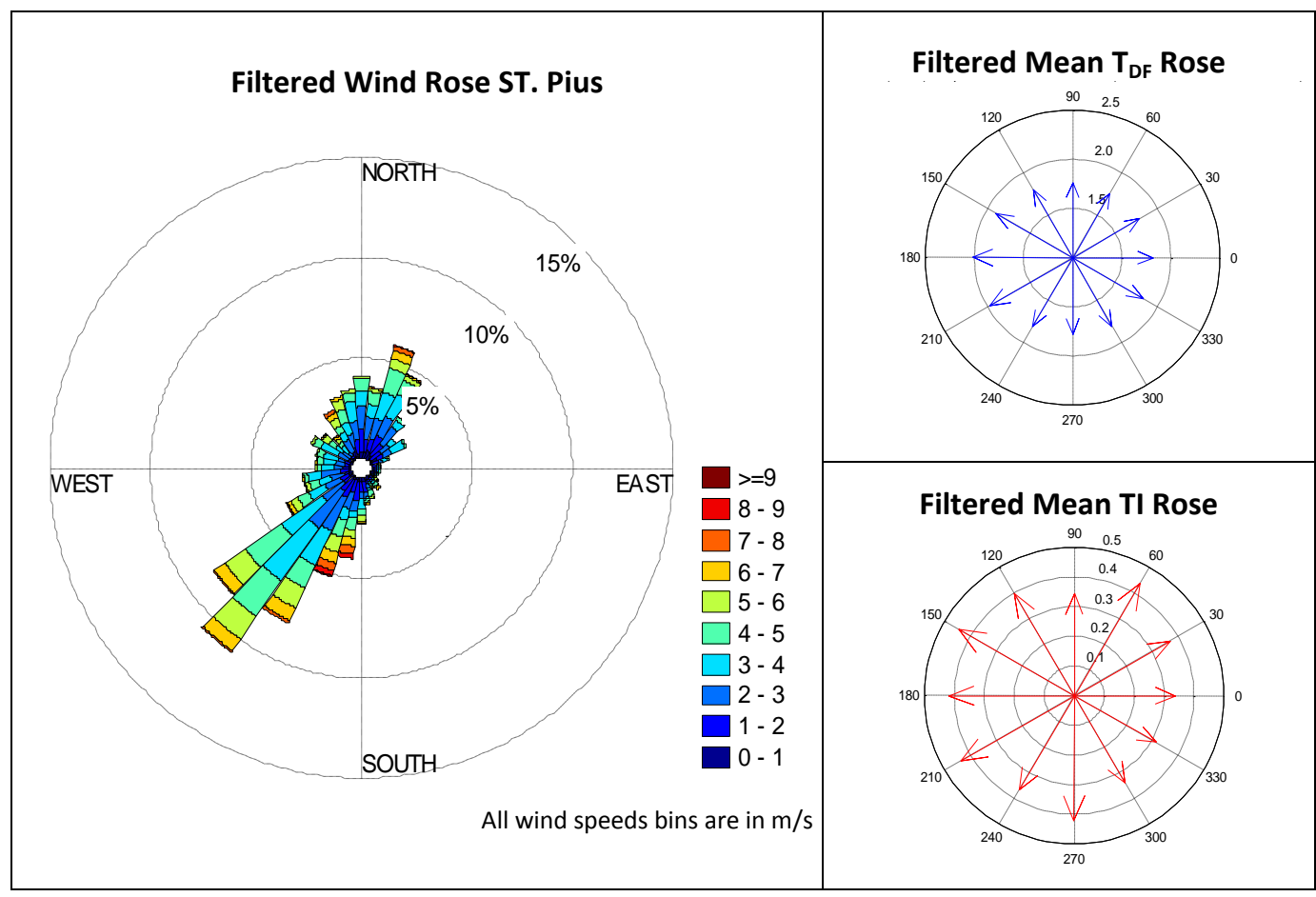

Figure 15 The concept of Rose diagrams in wind LHS frequency rose of wind speed Top Right mean $\mathrm{T}_{\mathrm{Df}}$ in a given Direction and Bottom Right mean $\mathrm{TI}$ in a given direction

\subsection{Turbulence Prediction}

An approach to ascertain if there is any means to approximate turbulence in a given direction is being developed that is employing aerial photographs to see if there is any correlation between for example edge detection / lacunarity in a given direction compared to turbulence. It would be a welcome advantage if statistical power prediction could be achieved without the cost of installation 
of a meteorological mast for a given site and hence this justifies the need for investigation in this area.

\section{CONCLUSION AND DISCUSSION}

It is evident that the current uncertainty associated with the turbulence classification in an urban context poses many challenges to micro wind installation designers. These challenges pose significant difficulties to our limited understanding as to what turbulence is and more importantly how it affects micro wind energy systems. While it can be argued that the $\mathrm{T}_{\mathrm{Df}}$ model is mathematically less intensive to compute due to its inherent reliance on the Fast Fourier Transform, it must also be remembered that it is not designed to measure turbulence in a similar manner to TI. That said, the $\mathrm{T}_{\mathrm{Df}}$ methodology appears to present a more coherent means of classifying a site's turbulence level as suggested in Figure 5. There is however, limited correlation between the two metrics across a range of turbulent environments. A simple scenario below explains the reasoning why this is the case.

Consider a gradually increasing wind speed over a 10 minute period shown in Figure 16.

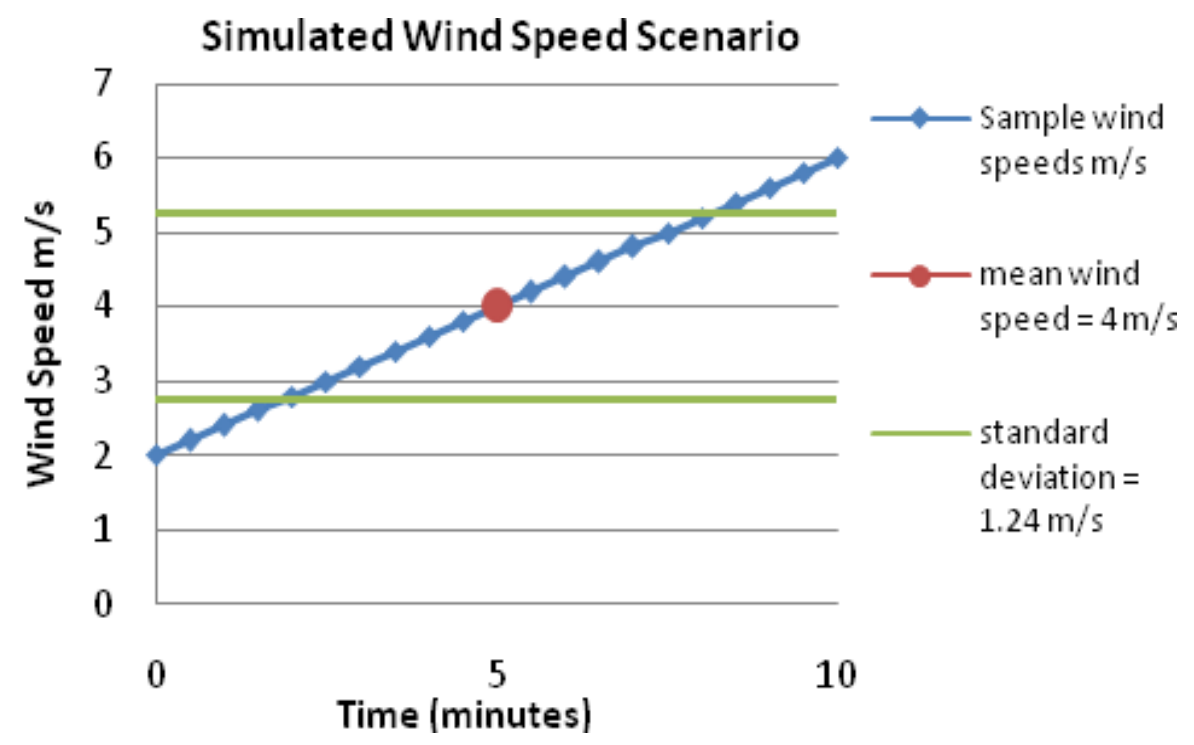

Figure 16 Wind speed scenario $\mathrm{Tl}=31 \% \mathrm{~T}_{\mathrm{Df}}=1$

The trend is totally persistent in nature i.e. $\mathrm{T}_{\mathrm{Df}}=1$ and therefore having no turbulence by the $\mathrm{T}_{\mathrm{Df}}$ metric. If we consider the same scenario from a TI perspective it has a value of $31 \%$. So is the scenario turbulent or not?

It is also noted that there is currently no means of classifying how much turbulence is dependent upon directionality and therefore the concept of a Turbulence Rose may need to be investigated as a tool for adequate site selection and classification.

The real question is not what we can mathematically measure but how this measurement affects the power performance of a microturbine scenario. To this end the TI metric is still the optimal metric for ascertaining power performance mathematically. It also has the ability to compress 10 minutes of data to just 2 datums (average wind speed and standard deviation) with the ability to simulate the 10 minute period based on these 2 datums. 
The ongoing work by the authors intends to investigate an artificial wind speed model that encompasses both $\mathrm{TI}$ and $\mathrm{T}_{\mathrm{DF}}$. The proposed methodology in section 4.3 is the intended path at this time however like all research there is a certain level of uncertainty with this regard. Furthermore this only enforces the need for future work in this area in order to increase accuracy of power prediction models in turbulent environments.

\section{ACKNOWLEDGEMENTS}

The wind velocity data is graciously provided by Dr. Rowan Fealy, of the National University of Ireland, Maynooth (NUIM) and Dr. Gerald Mills, University College Dublin, (UCD) through the Dublin Urban Boundary Layer Experiment (DUBLex) collaboration. 


\section{REFERENCES}

[1] Wind Power Programme. (2013, 21st January). [on-line]. Available: http://www.windpower-program.com/small_turbines.htm

[2] H. A. Panofsky and J. A. Dutton, Atmospheric turbulence: models and methods for engineering applications: Wiley, 1984.

[3] P. A. C. Rocha, H. H. B. Rocha, F. O. M. Carneiro, M. E. Vieira da Silva, and A. V. Bueno, "k- $\omega$ SST (shear stress transport) turbulence model calibration: A case study on a small scale horizontal axis wind turbine," Energy, vol. 65, pp. 412-418, 2014.

[4] P. A. Davidson, Turbulence : An Introduction for Scientists and Engineers: An Introduction for Scientists and Engineers: OUP Oxford, 2004.

[5] A. W. Zing and W. S. Chepil, "Aerodynamics of Wind Erosion," Journal of the Society of Agricultural Engineers, vol. 31, pp. 269-284, 1950.

[6] L. Lyles, L. A. Disrud, and R. K. Krauss, "Turbulence Intensity as Influenced by Surface Roughness and mean velocity in a Wind-Tunnel Boundary Layer," The American Society of Agricultural Engineers, vol. 14, pp. 285-289, 1971.

[7] C. J. Legleiter, T. L. Phelps, and E. E. Wohl, "Geostatistical analysis of the effects of stage and roughness on reach-scale spatial patterns of velocity and turbulence intensity," Geomorphology, vol. 83, pp. 322-345, 2007.

[8] Mertens S., "Wind Energy in the Built Environment: Concentrator Effects of Buildings," $\mathrm{PhD}$, Technische Universiteit Delft, 2006.

[9] H.-C. Lim and T.-Y. Jeong, "Wind energy estimation of the Wol-Ryong coastal region," Energy, vol. 35, pp. 4700-4709, 2010.

[10] M. Abbes and J. Belhadj, "Wind resource estimation and wind park design in El-Kef region, Tunisia," Energy, vol. 40, pp. 348-357, 2012.

[11] United Nations Human Settlements Programme (UN-HABITAT). (2008, 18/11/2012). State of the World's Cities 2008/2009: Harmonious Cities, [on-line].

[12] Germany Trade and Invest. (2014, 5th February). Germany's E- Energy Model Projects [on-line]. Available: http://www.gtai.de/GTAI/Navigation/EN/Invest/Industries/Smarterbusiness/Smart-energy/germanys-energy-concept,did=323796.html

[13] W. Langreder, K. Kaiser, H. Hohlen, and J. Hojstrup, "Turbulence Correction for Power Curves," presented at the EWEC, London, 2004.

[14] A. Tindal, C. Johnson, M. LeBlanc, K. Harman, E. Rareshide, A. Graves, M, and G. America, H, "Site-specific adjustments to wind turbine power curves," presented at the AWEA Wind Power Conference, Houston, 2008.

[15] B. C. Cochran, "The Influence of Atmospheric Turbulenceon the Kinetic Energy AvailableDuring Small Wind TurbinePower Performance Testing," presented at the IEA Expert Meeting on: Power Performance of Small Wind Turbines Not Connected to The Grid, Soria, Spain, 2002.

[16] K. Sunderland, T. Woolmington, J. Blackledge, and M. Conlon, "Small wind turbines in turbulent (urban) environments: A consideration of normal and Weibull distributions for power prediction," Journal of Wind Engineering and Industrial Aerodynamics, vol. 121, pp. 70-81, 2013.

[17] J. Blackledge, E. Coyle, D. Kearney, N. McCoy, K. Sunderland, and T. Woolmington, "Analysis of Wind Velocity and the Quantification of Wind Turbulence in Rural and Urban Environments using the L'evy Index and Fractal Dimension," ISAST Transactions on Computers and Intelligent Systems, vol. 4, pp. 7-17, 2012.

[18] T. Woolmington, K. Sunderland, J. Blackledge, and M. Conlon, "The Quantification Of Wind Turbulence By Means Of The Fourier Dimension," presented at the Irish Signals and Systems Conference, LYIT Letterkenny, 2013.

[19] Campbell Scientific. (2011, CSAT3 , 3-D Sonic Anemometer. Available: http://www.campbellsci.com/csat3 
[20] IEC, "International Standard 61400-2. Wind Turbines - Part 2: Design requirements for small turbines," ed, 2006.

[21] B. B. Mandelbrot, The fractal geometry of nature. San Francisco: W.H. Freeman, 1982.

[22] B. B. Mandelbrot, Gaussian self-affinity and fractals : Globality, the earth, $1 / f$ noise and $R / S$. New York: Springer, 2001.

[23] M. J. Turner, J. M. Blackledge, and P. R. Andrews, Fractal Geometry in Digital Imaging, 1st ed. London: Academic Press, 1998.

[24] W. D. Lubitz, "Impact of ambient turbulence on performance of a small wind turbine," Linkoping, Sweden, 2011.

[25] A. Albers "Turbulence Normalisation of Wind Turbine Power Curve Measurements," Deutsche WindGuard Consulting GmbH,2009.

[26] Sunderland K. M., Mills G., and Conlon M. F, "Estimating the wind resource in an urban area: A case study of micro-wind generation potential in Dublin, Ireland," Journal of Wind Engineering and Industrial Aerodynamics, vol. 118, pp. 44-53, 2013. 


\section{APPENDIX A-1}

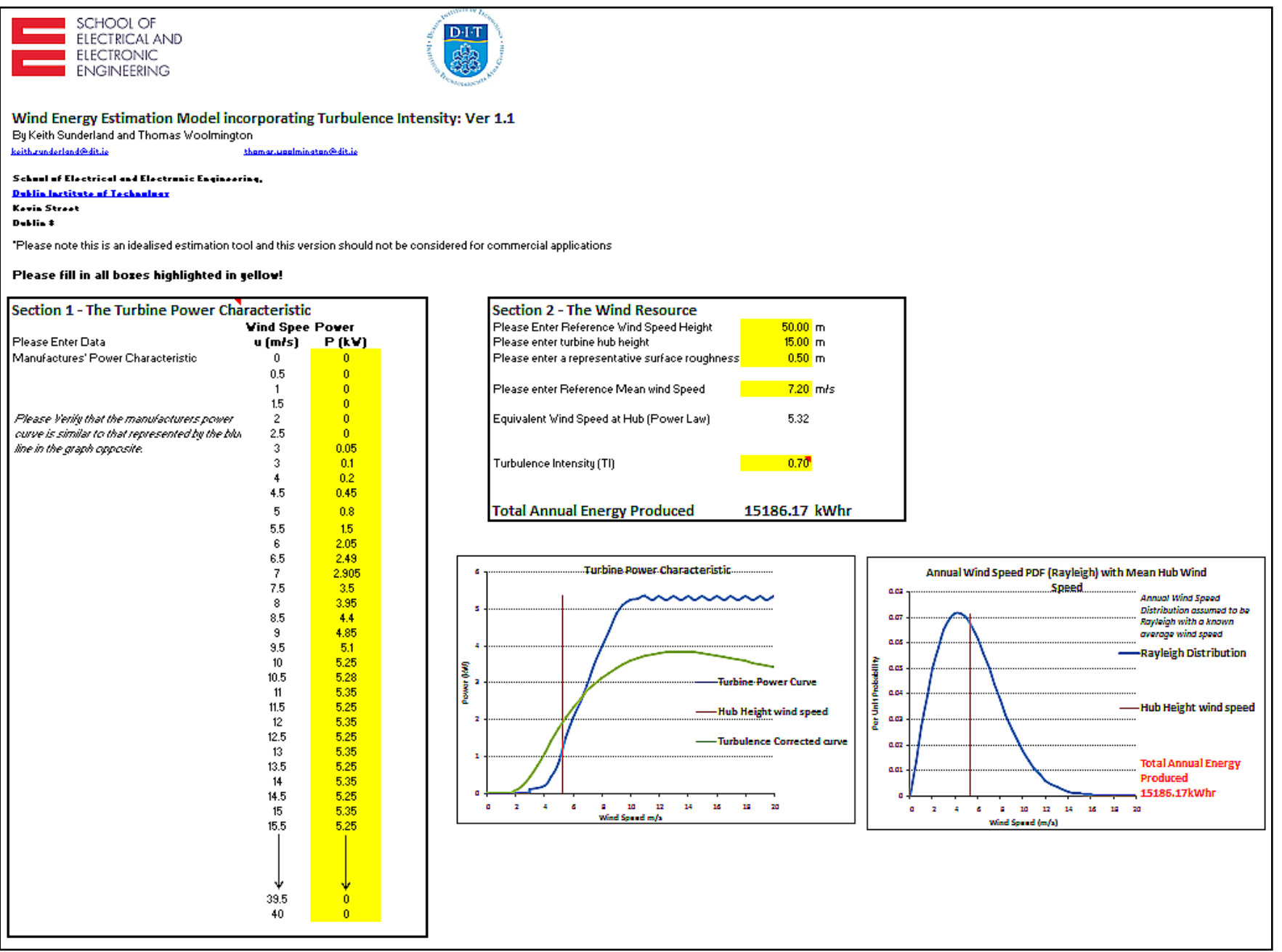

Figure A-1 Screen shot of SWEET (ver. 1.1) available at http://arrow.dit.ie/engschelecon/8/

This model presents a generic wind energy estimation tool that incorporates how turbulence intensity affects the power output of a (small) wind turbine.

Users of the model need to follow a number of guidance procedures as follows:

1. There are a number of assumptions underpinning the tool pertaining to the approximations employed

2. There are two distinct sections as illustrated in Fig. A-1; one defining the wind turbine characteristic and the other approximating both the available wind resource at the nacelle of the turbine and the influence of turbulence cognisant of the installation landscape (terrain roughness)

Section 1 Here the user can enter their own wind turbine characteristic (either as provided by the manufacturer or self generated)

Section 2 In section two the parameters that define the wind resource are defined, namely the reference wind speed, the height at which this wind speed is based, the turbine hub height and a general surface roughness parameter describing the landscape in which the turbine is installed. This section further facilitates a general quantification of TI - as expected at the location. 